\title{
Rheumatoid Factor Positivity and Ocular Manifestations among Rheumatoid Arthritis Patients - A Hospital-Based Cross-Sectional Study
}

\author{
Nishi Reghu Sathiamma ${ }^{1}$, Sheeba Chellan Shobhana², Jacob Antony³, Siji Vincent Swarna Bai ${ }^{4}$ \\ 1,2, 3 Department of Ophthalmology, GMC, Kollam, Kerala, India. \\ ${ }^{4}$ Department of Community Medicine, GMC, Kollam, Kerala, India.
}

\section{ABSTRACT}

\section{BACKGROUND}

RA Factor positivity is one of the criteria for diagnosis of Rheumatoid arthritis. High levels of rheumatoid factor (generally above $20 \mathrm{IU} / \mathrm{mL}$. 1:40 or over the $95^{\text {th }}$ percentile) are indicative of Rheumatoid arthritis (present in $80 \%$ ). Rheumatoid Factor positivity is associated with more severe and more active disease and extraarticular disease. This study was done in Rheumatoid arthritis patients to assess the proportion of ocular manifestations in them and also an association between RF positivity and ocular manifestation and treatment-related ocular complications among Rheumatoid arthritis patients.

\section{METHODS}

A cross-sectional study was conducted among the patients attending the rheumatology clinic at Government Medical College, Trivandrum. Patients in the age group of 18-60 years who satisfied the American Rheumatism Association criteria were selected for the study and all of them underwent complete ophthalmic examination as well as RA Factor assessment by latex agglutination. The qualitative variables were expressed in proportion. The chi-square test was used to determine the association between qualitative variables.

\section{RESULTS}

A total of 67 RA patients were screened of which 26 (38.8\%) had ocular manifestations and among the total patients, 57 (85\%) were rheumatoid factor positive. Among the total patients with ocular manifestations, 24 (92\%) patients were rheumatoid factor positive. The association between RF positivity and ocular manifestation was found to be statistically not significant (P-value -0.33). In the present study, no other treatment-related ocular complications were seen except for one patient on long term steroids who had subcapsular cataract.

\section{CONCLUSIONS}

The presence of the RA factor does not show a positive association with the occurrence of ocular manifestation and the use of a low dose of methylprednisolone and DMARDs in RA has reduced the incidence of steroid-related complications. The more commonly used DMARDs -methotrexate, salazopyrin and hydroxychloroquine were found to be safe since no drug toxicity was noted in the present study.

\section{KEY WORDS}

RA Factor, Rheumatoid arthritis, Ocular Manifestation.
Corresponding Author: Dr. Nishi Reghu Sathiamma, Rohini, TC 9/168,

Kallampally Medical College, P.O. Thiruvananthapuram-695011, Kerala, India.

E-mail:drnishi.rs@gmail.com

DOI: $10.14260 /$ jemds/2021/801

How to Cite This Article:

Sathiamma NR, Shobhana SC, Antony J, et al. Rheumatoid factor positivity and ocular manifestations among rheumatoid arthritis patients - a hospital based cross-sectional study. $J$ Evolution Med Dent Sci 2021;10(45):3968-3972, DOI: $10.14260 /$ jemds/2021/801

Submission 26-10-2021,

Peer Review 15-12-2021,

Acceptance 21-12-2021,

Published 28-12-2021.

Copyright (C) 2021 JEMDS. This is an open access article distributed under Creative Commons Attribution License [Attribution 4.0 International (CC BY 4.0)] 


\section{BACKGROUND}

The American College of Rheumatology has defined (1987) rheumatoid factor at a level above the 95th percentile as a criterion for the diagnosis of Rheumatoid arthritis.

Inflammatory mediators in Rheumatoid arthritis in addition to activating synovial cells to secrete inflammatory mediators, IL-I and TNF also have profound systemic effects. $\mathrm{RF}$ positivity is one of the criteria for the diagnosis of RA. High levels of RF (generally above $20 \mathrm{IU} / \mathrm{mL}$. 1:40 or over the 95th percentile) are indicative of Rheumatoid arthritis (present in $80 \%$ ) and Sjögren's syndrome (present in $60 \%$ ). There is a high rate of false positives due to other causes like chronic hepatitis, any chronic viral infection, leukaemia, dermatomyositis, infectious mononucleosis, scleroderma, systemic lupus erythematosus (SLE)

$\mathrm{RF}$ is a subset of antiglobulin antibodies directed against the Fc region of $1 \mathrm{gC}$. Reported by Waaler in 1940 and rediscovered by Rose in 1948, it sowed the seed of immunological interpretation of pathogenesis in connective tissue diseases. $\mathrm{RF}$ is produced by peripheral blood and synovial (CD 5) B cells and can comprise any of the major immunological interpretations of pathogenesis in connective tissue diseases. RF produced by peripheral blood and synovial (CD 5) B cells can comprise any of the major immunoglobulin classes IgG, IgA, IgE. The major source of RF is the inflamed synovium. The majority of the synovial immunoglobulin belongs to IgG class with $10 \%$ IgA and $10 \%$ IgM. However, only 2-6\% of this IgG has demonstrable RF activity, role of RF in the pathogenesis of RA lies in its ability to bind complement and activate natural killer cells to produce cytokines in the joint. RF may precede the onset of RA by several years and may not correlate with disease activity during early RA. However, later on, high titers of RF are known to be associated with more severe disease, extraarticular manifestations and rheumatoid nodules. RF is found in $5 \%$ of a healthy population and its frequency increases to $10-20 \%$ in individuals more than 65 years of age. The prognosis of RA is worse with a high titre of RF at the onset. Up to $20 \%$ of RA patients remain RF negative throughout the disease course. Several tests are available for measurement of RA namely:

\section{Agglutination Method \\ Latex fixation test or Bentonite flocculation test- RE is measured classically by the agglutination method, which is the most sensitive method. \\ - Enzyme-linked immunosorbent assay (ELISA) \\ - Laser nephelometry \\ - Radioimmunoassay (RIA)}

In summary, test for RF is not diagnostic of Rheumatoid arthritis but can be employed to confirm a diagnosis in an individual with clinical presentation suggestive of RA, and if present in high titre, to designate such patients at risk for severe systemic disease.

\section{Treatment}

Pharmacological treatment of RA can be divided into diseasemodifying antirheumatic drugs (DMARDs), anti-inflammatory agents and analgesics. DMARDs have been found to produce durable remissions and delay or halt disease progression. In particular, they prevent bone and joint damage from occurring secondary to uncontrolled inflammation. This is important as such damage is usually irreversible. Antiinflammatory and analgesics improve pain and stiffness but do not prevent joint damage or slow the disease progression.

\section{Disease-Modifying Anti-Rheumatic Drugs (DMARDs)}

DMARDs can be further subdivided into xenobiotic agents and biological agents. Xenobiotic agents are those DMARDs that do not occur naturally in the body, as opposed to biological.

Xenobiotics include azathioprine, cyclosporine (cyclosporine A), D-penicillamine, leflunomide, methotrexate (MTX), minocycline, sulfasalazine (SSZ)

\section{Biological Agents Include}

Tumour necrosis factor (TNF) blockers - etanercept (Enbrel), infliximab (Remicade), adalimumab (Humira), Interleukin-1 blockers - anakinra Anti-B cell (CD20) antibody - rituximab (Rituxan), Blockers of T cell activation - abatacept (Orencia)

Anti-inflammatory agents include: Glucocorticoids, Non steroidal anti-inflammatory drugs (NSAIDs, most also act as analgesics) Analgesics include acetaminophen, opiates, lidocaine topical

\section{Methotrexate}

It is the most popular first-line DMARD agent because of its early onset of action (4-6 weeks). Methotrexate is effective in reducing the signs and symptoms of RA, as well as slowing or halting radiographic damage. Hepatotoxicity, interstitial pneumonitis and myelosuppression are the significant side effects.

\section{Hydroxychloroquine}

It is an antimalarial drug. Usual dose is $6 \mathrm{mg} / \mathrm{kg} / \mathrm{day}$. It usually takes 2-4 months for effects to appear. Side effects include corneal deposits, extraocular muscular weakness, loss of accommodation and retinopathy that may progress to irreversible visual loss.

\section{Sulfasalazine}

Like other DMARDs, it not only reduces the signs and symptoms of RA but also slows the radiographic progression. The usual dose is $2-3 \mathrm{~g}$ /day in a twice-daily dose regimen.

\section{Leflunomide}

It inhibits tyrosine kinase activity and inhibits de novo pyrimidine biosynthesis through inhibition of mitogen and IL - 2 stimulated $\mathrm{T}$ - cells, dosage is $100 \mathrm{mg}$ daily for three days 
followed by $20 \mathrm{mg}$ daily. Side effects include GI intolerance and hepatotoxicity.

\section{Tumour Necrosis Factor Inhibitors}

TNF alpha is a pro-inflammatory cytokine produced by macrophages and lymphocytes. It is found in large quantities in the rheumatoid joints and is produced locally in the joint by synovial macrophages and lymphocytes infiltrating the joint synovium, TNF inhibitors are etanercept, infliximab and adalimumab 83, 84

\section{Soluble Interleukin - 1 Receptor Therapy}

IL -1 is a cytokine that has immune and pro-inflammatory actions and can regulate its expression by autoinduction. The level of disease activity in RA and progression of joint destruction correlate with plasma and the synovial fluid level of IL - 1

Anakinra is a human recombinant IL -1 receptor antagonist 81. It is not used with TNF blocking agents; dose is $100 \mathrm{mg} /$ day subcutaneous injection. It takes 2-4 weeks for effects to appear. Side effects include injection site reaction and decrease in neutrophil counts.

\section{Intramuscular Gold}

It is now rarely used due to its side effects and very slow onset of action.

\section{Cytotoxic Agents}

The most commonly used drugs are:

\section{Azathioprine}

It is a purine analogue that can cause severe bone marrow suppression particularly in patients with renal insufficiency or when used concomitantly with allopurinol or ACE inhibitors.

\section{Cyclophosphamide}

It is an alkylating agent with serious toxicities including bone marrow suppression, haemorrhagic cystitis, premature, ovarian failure, infection and secondary malignancy particularly an increased risk of bladder cancer. It is used for rheumatoid vasculitis or lung diseases.

\section{Cyclosporine}

It is an immunosuppressive agent which inhibits T-cell function by inhibiting transcription of IL-2. Main toxicity includes infection and renal insufficiency.

\section{Surgical Treatment}

Pain and joint mobility may be improved by surgeries. Total joint arthroplasties particularly of the knee, hip, wrist, and elbow are highly successful. Other operations include the release of nerve entrapment, arthroscopic procedures, and occasionally removal of a symptomatic rheumatoid nodule.

\section{METHODS}

This cross-sectional study was conducted at the Rheumatology Clinic of Trivandrum Medical College from August 2005 to August 2007. 67 diagnosed Rheumatoid arthritis patients were included in the study.

\section{Inclusion Criteria}

Patients in the age group 18-60 years who satisfied American Rheumatism Association Criteria were included in the study. All patients were subjected to a detailed examination, which included history taking as to, age, the duration of disease, treatment taken, other systemic illness and ocular complaints. A detailed ocular examination was done using a torchlight and slit lamp. Detailed fundus examination was done to rule out maculopathy and any evidence of vasculitis using a direct ophthalmoscope, $90 \mathrm{D}$ and indirect ophthalmoscope.

Lacrimal secretion was measured using Schirmer's test I and II using Whatman filter paper No. 41. Lissamine green staining \& TBUT was done in these cases. The macular function was assessed using colour vision and Amsler's grid test. FFA, field analysis and B-Scan were ordered if necessary. Patients with ocular manifestations were given the standard treatment available.

RA Factor ${ }^{1}$ was screened in all the patients. Ocular complications of the drugs used for the treatment of RA were screened for in these patients. Ethical committee clearance was obtained from the Institution. Written informed consent was obtained from all the study participants.

\section{Statistical Analysis}

The quantitative variables were represented as proportion. The association between RA factor and ocular manifestation was done using the chi-square test.

\section{RESULTS}

\begin{tabular}{|ccc|}
\hline Patients & Number & Percentage \\
& Total N=67 & $\mathbf{1 0 0 \%}$ \\
Males & 13 & 19 \\
Females & 54 & 80.59 \\
\hline \multicolumn{3}{|c}{} \\
\hline
\end{tabular}

\begin{tabular}{|ccc|}
\hline Age Groups & \multicolumn{2}{c|}{$\begin{array}{c}\text { Number Percentage } \\
\text { Total N=67 100\% }\end{array}$} \\
$21-25$ & 5 & 7.5 \\
$26-30$ & 5 & 7.5 \\
$30-35$ & 7 & 10.4 \\
$36-40$ & 11 & 16.4 \\
$41-45$ & 8 & 11.9 \\
$46-50$ & 12 & 17.9 \\
$51-55$ & 9 & 13.4 \\
$56-60$ & 7 & 10.4 \\
$61-65$ & 2 & 2.9 \\
$66-70$ & 1 & 1.5 \\
\hline & Table 2. Age Distribution \\
\hline
\end{tabular}

\begin{tabular}{|ccc|}
\hline Duration (Yrs.) & \multicolumn{2}{c|}{$\begin{array}{c}\text { Number Percentage } \\
\text { Total N=67 100\% }\end{array}$} \\
$0-5$ & 43 & 64.2 \\
$6-10$ & 16 & 23.9 \\
$11-15$ & 4 & 5.9 \\
$16-20$ & 2 & 2.9 \\
$21-25$ & 2 & 2.9 \\
\hline \multicolumn{3}{|c}{ Table 3. Duration of Disease } \\
\hline
\end{tabular}




\begin{tabular}{|ccc|}
\hline Ocular Manifestations & Number N=67 & Percentage 100\% \\
$\begin{array}{c}\text { No. of patients having ocular } \\
\text { manifestations }\end{array}$ & 26 & $38.8 \%$ \\
$\begin{array}{c}\text { No. of patients not having Ocular } \\
\text { manifestation }\end{array}$ & 41 & $61.2 \%$ \\
\hline \multicolumn{2}{|c|}{ Table 4. Distribution of study participants based on Ocular } \\
Manifestations
\end{tabular}

\begin{tabular}{|ccc|}
\hline RF Positivity & Number N=67 & Percentage $\mathbf{1 0 0} \%$ \\
RF positive & 57 & $85 \%$ \\
RF Negative & 10 & $15 \%$ \\
\hline Table 5. Distribution of RF Positivity among & Total Patients \\
\hline
\end{tabular}

\begin{tabular}{|c|c|c|c|c|c|c|}
\hline \multirow[b]{2}{*}{ RF } & \multicolumn{4}{|c|}{ Ocular Manifestations } & \multirow[b]{2}{*}{$\begin{array}{c}\text { Chi-Square } \\
\text { Value }\end{array}$} & \multirow[b]{2}{*}{$\begin{array}{c}P \\
\text { Value }\end{array}$} \\
\hline & $\begin{array}{c}\text { Present } \\
(\mathrm{N}=26)\end{array}$ & $\begin{array}{c}\text { Present } \\
100 \%\end{array}$ & $\begin{array}{l}\text { Absent } \\
(\mathrm{N}=41)\end{array}$ & $\begin{array}{c}\text { Absent } \\
100 \%\end{array}$ & & \\
\hline $\begin{array}{c}\text { RF positive } \\
(\mathrm{N}=57)\end{array}$ & 24 & $43 \%$ & 33 & $57 \%$ & \multirow{2}{*}{0.94} & \multirow{2}{*}{$0.33^{*}$} \\
\hline $\begin{array}{c}\text { RF negative } \\
(\mathrm{N}=10)\end{array}$ & 2 & $20 \%$ & 8 & $80 \%$ & & \\
\hline \multicolumn{7}{|c|}{ Table 6. Ocular Manifestations with RF Positivity } \\
\hline
\end{tabular}

\begin{tabular}{|ccc|}
\hline Drugs & No. of Patients & Complications \\
Hydroxycholoroquine & 28 & 0 \\
Steroid (glucocorticosteroids) & 47 & 1 \\
Methotrexate & 40 & 0 \\
Sulfasalazine & 25 & 0 \\
\hline Table 7. Drugs Given for Patients with RA \& \\
Complications Noted \\
\hline
\end{tabular}

\section{DISCUSSION}

There were a total of 67 patients and 57 (85.1\%) of them were rheumatoid factor positive. ${ }^{1} \mathrm{RF}$ positivity in a study by Helio vaara et al. and Hakala et al. was $74 \% .^{2}$ The result of the present study was comparable to other studies. 24 (92.3 $\%)$ of the 26 patients with ocular manifestations were positive for rheumatoid factor. The association between RF and ocular manifestation in the present study (chi-square value $=0.94$; $\mathrm{P}$-value 0.33 , ) is not significant, while a study conducted by Matsuo et al. had suggested that ocular manifestation should be considered in patients with higher titers of rheumatoid factor and this result may be due to small sample size of the present study.

\section{Drug Toxicity}

Toxicity to hydroxychloroquine ${ }^{3,4}$ was looked for in patients on treatment with the same drug. 28 patients were on hydroxychloroquine.5,6 Mean duration was 1.5 years with a dose of $200 \mathrm{mg}$ BD. All these patients underwent a detailed fundus evaluation, Amsler grid testing, colour vision test and slit-lamp examination.7,8,9 Ocular complication was not seen in any of the patients. A dose of $6.5 \mathrm{mg} / \mathrm{kg} /$ day is considered safe as recommended by the American Academy of Ophthalmology.

47 patients were on systemic steroids. Most of these patients were on a low dose of methylprednisolone ${ }^{10,11}$ during the active phase of the disease and were tapered off when the disease was controlled with DMARD ${ }^{12,13,14}$ and when the disease was in remission. ${ }^{15}$ Only one patient had a posterior subcapsular cataract (2.1\%) and he was referred to the clinic after long periods of treatment with prednisolone elsewhere. In the study by Bogliolo A et al. ${ }^{16}$ (1993) incidence of posterior subcapsular cataracts was only $4 \%$. Our study shows concordance with the above-mentioned study.

\section{CONCLUSIONS}

The present study shows that the proportion of patients presenting with ocular manifestations was found to be high (85\%). The presence of rheumatoid factor in serum does not show a positive association with the occurrence of ocular manifestations in Rheumatoid arthritis. Drug-related ocular complications were found to be very low in the present study probably due to the use of (methylprednisolone) as the steroid in low doses, along with DMARD. The more commonly used DMARD - methotrexate, salazopyrin and hydroxychloroquine were found to be safe drugs since no ocular toxicity was noted in the study.

Data sharing statement provided by the authors is available with the full text of this article at jemds.com.

Financial or other competing interests: None.

Disclosure forms provided by the authors are available with the full text of this article at jemds.com.

\section{REFERENCES}

[1] Carson DA. Rheumatoid factor. In: Kelley WN, Harris ED, Ruddy S, et al: Text book of rheumatology. $3^{\text {rd }}$ edn. Philadelphia: Saunders 1989.

[2] Hakala M, Pöllänen R, Nieminen P. The ARA 1987 revised criteria select patients with clinical Rheumatoid arthritis from a population-based cohort of subjects with chronic rheumatic diseases registered for drug reimbursement. J Rheumatol 1993;20(10):1674-8.

[3] Nika M, Blachley TS, Edwards P, et al. Regular examinations for toxic maculopathy in long-term chloroquine or hydroxychloroquine users. JAMA Ophthalmol 2014;132(10):1199-208.

[4] Easterbrook M Ocular effect and safety of antimalarial agent. Am J Med 1988;85(4A):23-9.

[5] Neubauer AA, Samari-Kermani K, Schaller U, et al. Detecting chloroquine retinopathy: electro-oculogram versus colour vision. B J Ophthalmol 2003;87(7):902-8.

[6] Easterbrook M. Detection and prevention of maculopathy associated with antinmalarials agents. Int Ophthalmol Clin 1999;39(2):49-57.

[7] Wetterholm DH, Winter FC. Histopathology of chloroquine retinal toxicity. Arch Ophthalmol 1964;71(1):82-7.

[8] Bernstein HN. Ocular safety of hydroxychloroquine. Ann Ophthalmol 1991;23(8):299-6.

[9] Percival SP, Meanock I. Chloroquine: Ophthalmological Safety and clinical assessment in Rheumatoid arthritis. Br Med J 1968;3(5618):579-84.

[10] Saag KG, Koehnke R, Caldwell JR et al. Low dose long term corticosteroid therapy in Rheumatoid arthritis: an analysis of serious adverse events. Am J Med 1994;96(2):115-23.

[11] Da Silva JAP, Jacobs JWG, Kirwan JR, et al. Safety of low dose glucocorticoid treatment in Rheumatoid arthritis. Ann Rheum Dis 2006;65(3):285-93.

[12] Guideliness for the management of Rheumatoid arthritis. American college of Rheumatology AD Hoc Committee on clinical Guideliness. Arthritis Rheum 1996;39(5):71322. 
[13] Weisman MH, Winbaltt ME. Treatment of the rheumatic diseases, companion to the text book of rheumatology. Pheladelphia: WB Saunders 1995.

[14] Simon LS. Nonsteroidal anti-inflammatory drug toxicity. Curr Opin Rheumatol 1993;5(3):265-75.

[15] Maini RN, Breedveld FC, Kalden KR, et al. Therapeutic efficacy of multiple intravenous infusinos anti-tumor necrosis factor alpha monoclonal antibody combined with low dose weekly methotrexate in Rheumatoid arthritis. Arthritis Rheum 1998;41(9):1552-63.

[16] Bogliolo E, Mela Q, Perpignano L, et al Ocular involvement in Rheumatoid arthritis. Clin Terapeut 1993;142(1):41-6. 